\title{
Kinetic investigations on the esterification of phthalic anhydride with n-heptyl, n-nonyl or n-undecyl alcohol over sulfuric acid catalyst
}

\author{
Maria Kulawska • Henryk Moroz • \\ Aleksandra Kasprzyk
}

Received: 8 March 2011 / Accepted: 3 June 2011/Published online: 1 July 2011

(C) The Author(s) 2011. This article is published with open access at Springerlink.com

\begin{abstract}
Kinetic investigations on the syntheses of higher aliphatic alcohol $\left(\mathrm{C}_{7}\right.$, $\mathrm{C}_{9}, \mathrm{C}_{11}$ ) phthalates have been conducted in an isothermal, semibatch reactor. The first stage of the process, the formation of monoester, is very fast and irreversible. The second stage, the esterification of monoester towards diester, is slow and catalyst should be used. These reactions appear to be first order with respect to monoester and do not depend on the concentration of alcohol.
\end{abstract}

Keywords DHP · DNP · DUP · Esterification · Kinetics · Phthalic anhydride · Sulfuric acid

\section{Introduction}

Phthalates of higher aliphatic alcohols $\mathrm{C}_{7}, \mathrm{C}_{9}, \mathrm{C}_{11}$ are clear, oily liquids at room temperature, soluble in common organic solvents and miscible with other phthalates. Diheptyl phthalate (DHP), dinonyl phthalate (DNP, DINP), diundecyl phthalate (DUP) are mainly used as softeners of PVC (about 90\% of the production). The consumption of the softeners reaches five million tons each year in the world, in that about 2.7 millions tons constitute phthalates. Together they account for around $60 \%$ of all plasticizer use in Europe. DINP is a mixture of different isomers that have alkyl chains from 8 to 10 carbons long, but the largest portion of the mixture has chains composed of $\mathrm{C}_{9}$. The remaining DINP is used in polymer related-uses (e.g., rubbers), production printing inks and pigments, adhesives, sealants, paints, lacquers and lubricants. DUP is recommended for use in wire insulation at temperature about $370 \mathrm{~K}$. Phthalate blends of di(heptyl-nonyl)

M. Kulawska $(\bowtie) \cdot$ H. Moroz $\cdot$ A. Kasprzyk

Institute of Chemical Engineering, Polish Academy of Sciences,

ul. Baltycka 5, 44-100 Gliwice, Poland

e-mail: m.kul@iich.gliwice.pl 
phthalate and di(heptyl-nonyl-undecyl) phthalate are used for special applications $[1,2]$.

The synthesis proceeds in two stages: in the first, very fast and complete, monoheptyl phthalate is formed, in the second-diheptyl phthalate.

Similar formulas describe the esterification with $n$-nonyl alcohol and $n$-undecyl alcohol. Kinetic data concerning the synthesis of phthalates have not been found in literature. There are kinetic investigations of Skrzypek et al. [3, 4] on the esterification of phthalic anhydride with $\mathrm{C}_{6}$ and $\mathrm{C}_{8}$ alcohols, and recently, kinetic investigations on the esterification of phthalic anhydride with butyl alcohols [5]. The syntheses proceeded in the presence of sulfuric acid. Sulfuric acid is the classic catalyst of esterification. It gives the highest reaction rate, so it is a good starting point for wide kinetic investigations. The aim of our study was an investigation of the kinetics of the syntheses of phthalic anhydride with $n$-heptyl, $n$-nonyl or $n$-undecyl alcohol in the presence of sulfuric acid.

\section{Experimental}

Materials: phthalic anhydride and sulfuric acid, AR grade, purchased from POCH SA Gliwice, Poland; n-heptyl alcohol, n-nonyl alcohol, n-undecyl alcohol, AR grade, were all purchased from SIGMA-ALDRICH.

Reaction 1 goes with very high rate, so our investigations concerned reaction 2 .<smiles>O=c1c(=O)c(=O)c2ccccc2c1=O</smiles>

$\mathrm{O}$

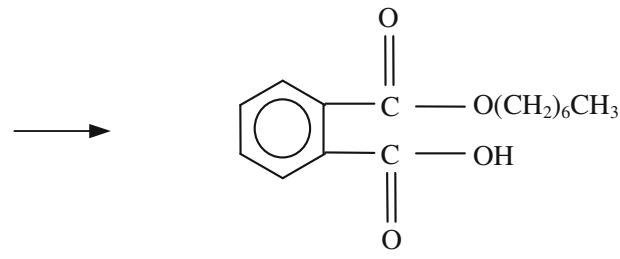

(1)

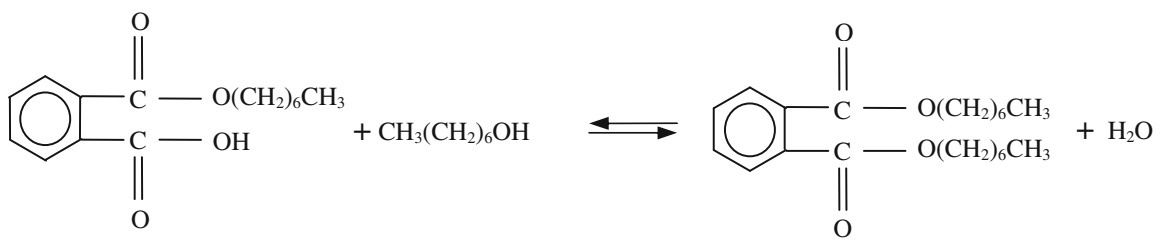

The experimental set and the experimental procedure have been described earlier [3]. The main component of the apparatus was a glass flask of $1 \mathrm{dm}^{3}$ volume placed in a thermostat. The reactor was equipped with a thermometer, sampling cock, azeotropic head with a cooler and a magnetic stirrer of 1,040 rpm. The experiments were carried out in the range of initial mole ratios of alcohol to phthalic anhydride, $b=c^{0}{ }_{\text {ALC }} / c^{0}{ }_{\text {PHT }}$, equal to $3: 1,5: 1,10: 1$. The effect of temperature on the reaction 
rate was determined at $b=5: 1$, in the range of temperatures $413-453 \mathrm{~K}$. The concentration of catalyst was 0.1 mass $\%$ in the series of $n$-heptanol esterification; and 0.05 mass $\%$ in the series of $n$-nonanol and $n$-undecanol esterification. All experiments were conducted under atmospheric pressure. Chromatographic analyses of random samples of the reacting liquid practically did not reveal the presence of any by-products. A Perkin-Elmer gas chromatograph of Clarus 500 type was used to analyze products, with flame ionization detector (FID), capillary non polar column Elite-5, $30 \mathrm{~m} \times 0.32 \mathrm{~mm}$ (film thickness $0.25 \mu \mathrm{m}$ ). Sample volume $0.5 \mu \mathrm{L}$ (autosampler), split 50:1 was used. Temperature program: $60{ }^{\circ} \mathrm{C}(2 \mathrm{~min}), 20^{\circ} \mathrm{C} / \mathrm{min}$, $300{ }^{\circ} \mathrm{C}(5 \mathrm{~min})$.

The equipment used enables water to be removed instantaneously and completely from the reacting mixture. For good efficiency of removal of water and consequently elimination of the hydrolysis of ester, we have used a sufficiently high flow of inert gas. The level of the nitrogen flow was determined experimentally by using progressively increasing nitrogen flow rates. A maximum limiting value of the flow was thus established, above which further increase in the flow rate has no effect. Under these conditions the reaction 2 can be assumed as irreversible.

Conversion of phthalic anhydride was calculated from the following formula:

$$
\eta=\frac{A N^{\circ}-A N\left(\frac{56100-18 A N^{\circ}}{56100-18 A N}\right)}{A N^{\circ}}
$$

where $A N^{\mathrm{o}}$ is the initial acid number of the reaction system, $A N$ is the acid number after a reaction time, 56100 is an analytical factor-the molar mass of $\mathrm{KOH}(\mathrm{mg} /$ $\mathrm{mol}$ ) and 18 is the molar mass of water $(\mathrm{g} / \mathrm{mol})$. Eq. 3 takes into account the decrease in the total reaction mass due to removal of water from the system during the course of the reaction. The calculation was based on the acid number determination in the samples taken from the reacting mixture. The course of the acid number during the reaction with $n$-heptyl alcohol over 0.10 mass $\%$ sulfuric acid catalyst as a time function at constant temperature and various $b$ is shown in Fig. 1. These series of experiments have been conducted to determine the rate equation. The course of the acid number during the reaction with $n$-heptyl alcohol over 0.10 mass $\%$ sulfuric acid catalyst at $b$ constant and various temperatures is shown in Fig. 2. These series of experiments have been conducted to determine the effect of temperature on the reaction rate. Similar curves have been obtained during the reactions with $n$-nonyl and $n$-undecyl alcohol over 0.05 mass $\%$ sulfuric acid catalyst.

\section{Results}

The reaction rate constant has been derived using a trial and error method by assuming various kinetic equations with various reaction orders from experiments at constant temperature. The experimental results prove that the reaction rate depends on the concentration of acid, i. e., monoester only. The reaction rate constant has been also estimated by the integrating method, after arrangement and integration of the classic batch reactor mass balance equation with concentrations expressed by conversion. 


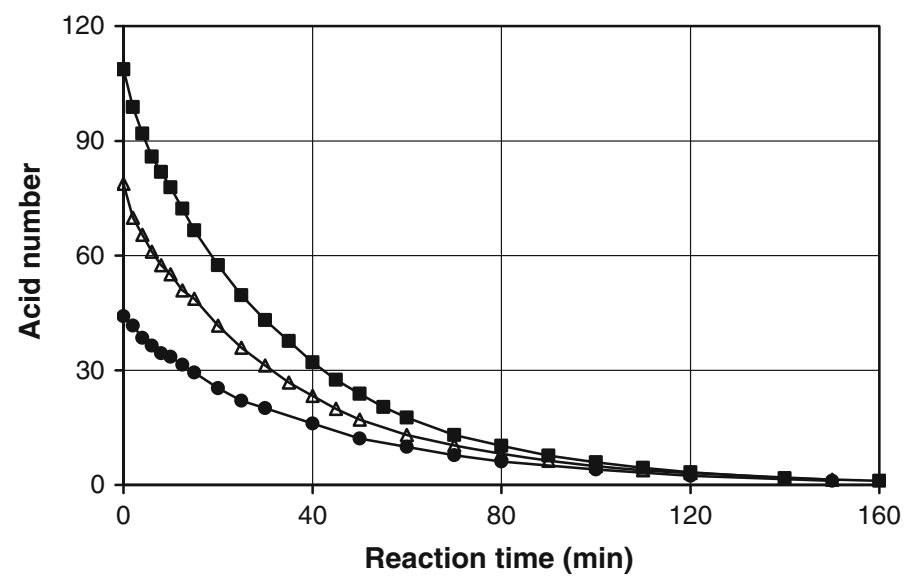

Fig. 1 Course of acid number during $n$-heptanol esterification over 0.1 mass $\%$ sulfuric acid catalyst, for various mole ratios of substrates, $b$, at 433 K. $b=3: 1$ (closed square), 5:1 (open triangles), 10:1 (closed circles)

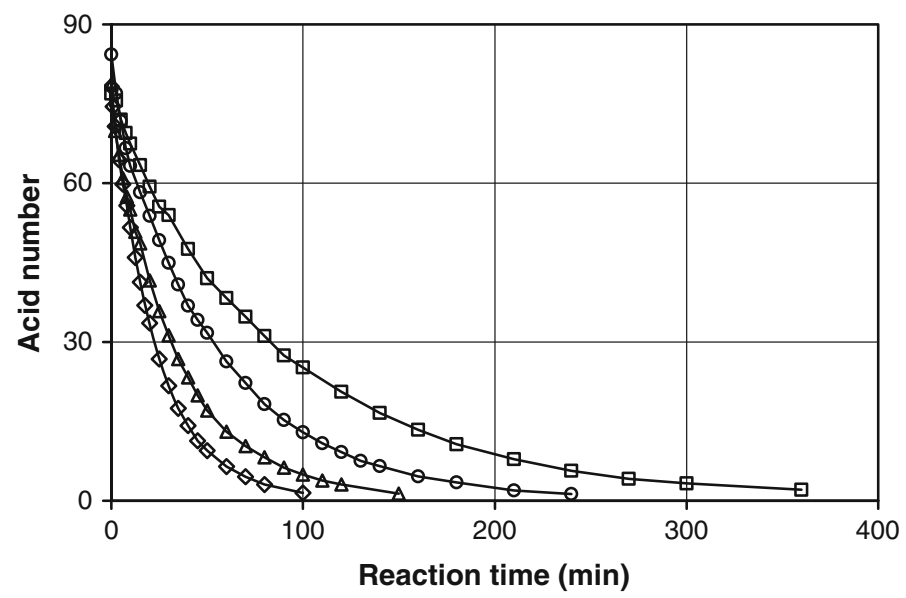

Fig. 2 Course of acid number during $n$-heptanol esterification over 0.1 mass $\%$ sulfuric acid catalyst at $b=5: 1 . T=413 \mathrm{~K}$ (open square), $423 \mathrm{~K}$ (open circles), $433 \mathrm{~K}$ (open triangles), $443 \mathrm{~K}$ (open diamonds)

$$
r=-\mathrm{d} c_{m} / \mathrm{d} \tau=k c_{m}
$$

The reaction rate constant $k$ is a product of reaction rate constant, independent of catalyst concentration, and concentration of catalyst. A linear relation between reaction rate constant and concentration of catalyst has been confirmed in many articles, among them, also in our previous study [3].

$$
k=k \prime \cdot c_{c a t}
$$

The reactions investigated appear to be of the first order with respect to acid (i.e., monophthalate of respective alcohol) and zeroth order with respect to alcohol. Such 


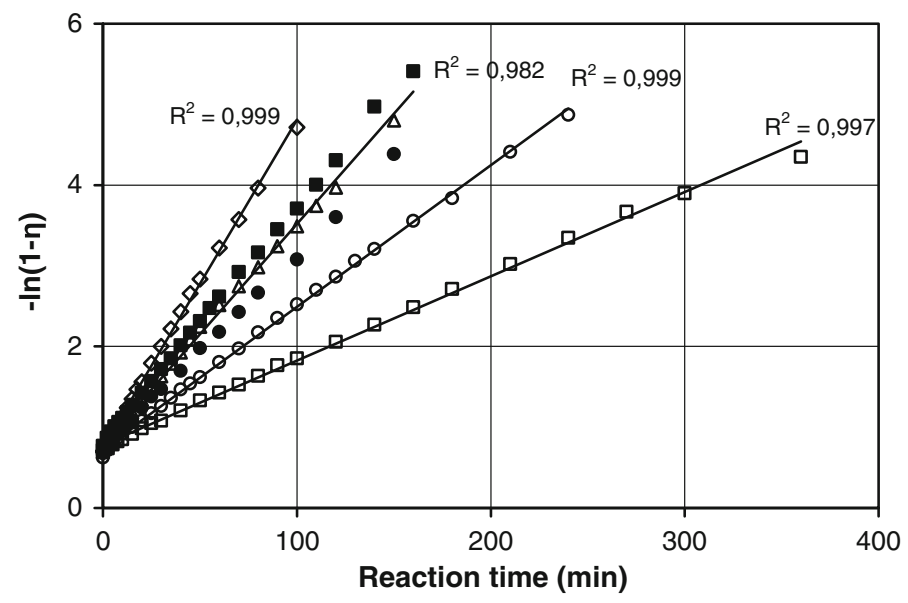

Fig. 3 Quality of fit to the experimental data obtained for the esterification of phthalic anhydride with $n$ heptanol over 0.1 mass $\%$ sulfuric acid catalyst at $b=5: 1 . T=413 \mathrm{~K}$ (open square), $423 \mathrm{~K}$ (open circles), $433 \mathrm{~K}$ (open triangles), $443 \mathrm{~K}$ (open diamonds) and $T=433 \mathrm{~K}: b=3: 1$ (closed square), 10:1 (closed circles)

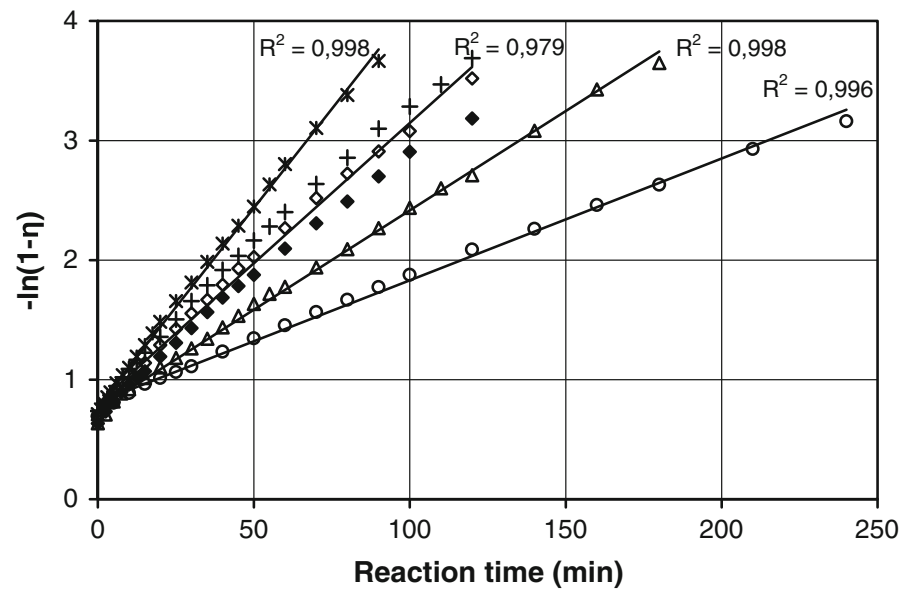

Fig. 4 Quality of fit to the experimental data obtained for the esterification of phthalic anhydride with $n$ nonanol over 0.05 mass\% sulfuric acid catalyst at $b=5: 1 . T=423 \mathrm{~K}$ (open circles), $433 \mathrm{~K}$ (open triangles), $443 \mathrm{~K}$ (open diamonds), $453 \mathrm{~K}$ (asterisk) and $T=443 \mathrm{~K}: b=3: 1$ (plus), $10: 1$ (closed diamonds)

a relationship has also been found in the cited works of Skrzypek et al. [3-5]. The goodness of fit to experimental data obtained for the esterification of phthalic anhydride with $n$-heptyl, $n$-nonyl or $n$-undecyl alcohol over sulfuric acid catalyst is shown in Figs 3, 4 and 5.

The activation energy has been derived from the Arrhenius plot on the base of mean values of reaction rate constants from experiments at various temperatures. 


$$
k=k_{0} \exp \left(-E_{\mathrm{a}} / R T\right)
$$

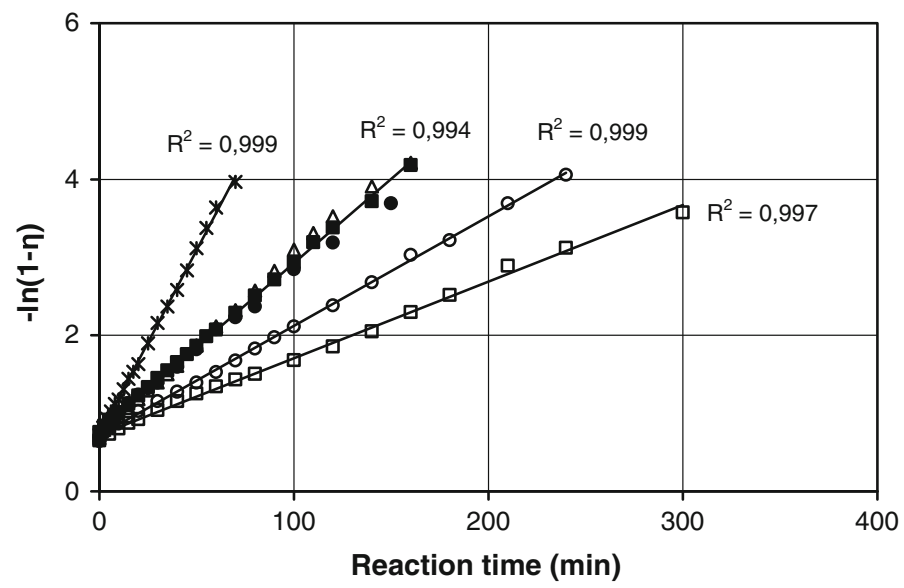

Fig. 5 Quality of fit of the experimental data obtained for esterification of phthalic anhydride with $n$ undecanol over 0.05 mass $\%$ sulfuric acid catalyst at $b=5: 1 . T=413 \mathrm{~K}$ (open square), $423 \mathrm{~K}$ (open circles), $433 \mathrm{~K}$ (open triangles), $453 \mathrm{~K}$ (asterisk) and $T=433 \mathrm{~K}: b=3: 1$ (closed square), 10:1 (closed circles)

Table 1 Phthalic anhydride esterification with various alcohols over sulfuric acid catalyst

\begin{tabular}{|c|c|c|c|c|c|c|}
\hline $\begin{array}{l}\text { Alcohol/ } \\
\text { catalyst } \\
\text { concentration }\end{array}$ & $\begin{array}{l}\text { Temperature } \\
T(\mathrm{~K})\end{array}$ & $\begin{array}{l}\text { Mole } \\
\text { ratio } \\
c^{0}{ }_{\mathrm{ALC}}^{\prime} \\
c^{0}{ }_{\mathrm{PHT}}\end{array}$ & $\begin{array}{l}\text { Reaction } \\
\text { time } \\
(\mathrm{min})\end{array}$ & Conversion & $\begin{array}{l}\text { Preexponential } \\
\text { factor } k_{0} \\
\left(\min ^{-1}\right)\end{array}$ & $\begin{array}{l}\text { Activation } \\
\text { energy } E_{\mathrm{a}} \\
\left(\mathrm{kJ} \mathrm{mol}^{-1}\right)\end{array}$ \\
\hline \multirow{8}{*}{$\begin{array}{l}n \text {-Heptyl/0.1 } \\
(\text { mass \%) }\end{array}$} & \multirow[t]{4}{*}{433} & $3: 1$ & 160 & 0.996 & & \multirow{8}{*}{68.3} \\
\hline & & $5: 1$ & 150 & 0.992 & & \\
\hline & & $10: 1$ & 150 & 0.988 & & \\
\hline & & & & & $4.64 \times 10^{6}$ & \\
\hline & 413 & \multirow[t]{4}{*}{$5: 1$} & 360 & 0.987 & \multirow{4}{*}{$\begin{array}{l}\text { Experimental error } \\
\quad \pm 4 \%\end{array}$} & \\
\hline & 423 & & 240 & 0.992 & & \\
\hline & 433 & & 150 & 0.992 & & \\
\hline & 443 & & 100 & 0.991 & & \\
\hline \multirow{8}{*}{$\begin{array}{c}n \text {-Nonyl/0.05 } \\
(\text { mass \%) }\end{array}$} & \multirow[t]{4}{*}{443} & $3: 1$ & 360 & 0.993 & & \\
\hline & & $5: 1$ & 210 & 0.990 & & \\
\hline & & $10: 1$ & 240 & 0.988 & & \\
\hline & & & & & $4.64 \times 10^{5}$ & 62.0 \\
\hline & 423 & \multirow[t]{4}{*}{$5: 1$} & 600 & 0.989 & \multirow{4}{*}{$\begin{array}{l}\text { Experimental error } \\
\quad \pm 3 \%\end{array}$} & \\
\hline & 433 & & 270 & 0.990 & & \\
\hline & 443 & & 210 & 0.990 & & \\
\hline & 453 & & 150 & 0.990 & & \\
\hline
\end{tabular}


Table 1 continued

\begin{tabular}{|c|c|c|c|c|c|c|}
\hline $\begin{array}{l}\text { Alcohol/ } \\
\text { catalyst } \\
\text { concentration }\end{array}$ & $\begin{array}{l}\text { Temperature } \\
T(\mathrm{~K})\end{array}$ & $\begin{array}{l}\text { Mole } \\
\text { ratio } \\
c^{0}{ }_{\text {ALC }} \\
c^{0}{ }_{\text {PHT }}\end{array}$ & $\begin{array}{l}\text { Reaction } \\
\text { time } \\
(\mathrm{min})\end{array}$ & Conversion & $\begin{array}{l}\text { Preexponential } \\
\text { factor } k_{0} \\
\left(\min ^{-1}\right)\end{array}$ & 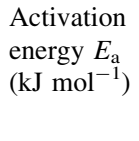 \\
\hline \multirow{8}{*}{$\begin{array}{l}n \text {-Undecyl/0.05 } \\
(\text { mass \%) }\end{array}$} & \multirow[t]{4}{*}{433} & $3: 1$ & 240 & 0.994 & & \\
\hline & & $5: 1$ & 240 & 0.991 & & \\
\hline & & 10:1 & 180 & 0.985 & & \\
\hline & & & & & $1.31 \times 10^{6}$ & 64.6 \\
\hline & 413 & \multirow[t]{4}{*}{$5: 1$} & 420 & 0.989 & \multirow{4}{*}{$\begin{array}{l}\text { Experimental error } \\
\quad \pm 2.7 \%\end{array}$} & \\
\hline & 423 & & 300 & 0.989 & & \\
\hline & 433 & & 240 & 0.991 & & \\
\hline & 453 & & 100 & 0.992 & & \\
\hline
\end{tabular}

The values of activation energy $E_{\mathrm{a}}$ and the values of pre-exponential factor $k_{0}$ are given in Table 1.

Kinetic data for the syntheses of phthalates of higher aliphatic alcohols could be interesting from both theoretical and practical points of view.

Open Access This article is distributed under the terms of the Creative Commons Attribution Noncommercial License which permits any noncommercial use, distribution, and reproduction in any medium, provided the original author(s) and source are credited.

\section{References}

1. Wardzińska E, Pęczek P (2002) Przem Chem 81(12):792-797

2. The European Council for Plasticisers and Intermediates (ECPI) (2009) The Phthalates Information Centre. Brussels, Belgium

3. Skrzypek J, Sadłowski JZb, Lachowska M, Turzański M (1994) Chem Eng Process 33:413-418

4. Grzesik M, Skrzypek J, Małota P, Moroz H (2002) Inż Chem Proc 23:301-308

5. Skrzypek J, Kulawska M, Lachowska M, Moroz H, Kasprzyk A (2010) Przem Chem 89(3):246-248 